\title{
Achieving Quality in Community Health Care Nursing
}




\section{Community Health Care Series}

Deborah Hennessy (editor)

Community Health Care Development

Carolyn Mason (editor) Achieving Quality in Community Health Care Nursing

John Øvretveit, Peter Mathias and Tony Thompson (editors)

Interprofessional Working for Health and Social Care

\section{Series Standing Order}

If you would like to receive future titles in this series as they are published, you can make use of our standing order facility. To place a standing order please contact your bookseller or, in case of difficulty, write to us at the address below with your name and address and the name of the series. Please state with which title you wish to begin your standing order. (If you live outside the UK we may not have the rights for your area, in which case we will forward your order to the publisher concerned.)

Standing Order Service, Macmillan Distribution Ltd,

Houndmills, Basingstoke, Hampshire, RG21 6XS, England 


\section{Achieving Quality in Community Health Care Nursing}

Edited by

CAROLYN MASON 
Selection and Preface (C) David Sines 1997

Editorial matter, Introduction and Chapter 1 (C) Carolyn Mason 1997

Foreword (C) Judith F. Hill 1997

Individual chapters (in order) (C) Brenda C. Poulton, David C. Benton, Maura Pidgeon, Hugh McKenna, Alison While, Robert Stewart and Ian Turner, Ann Long, Kate Cernik 1997

All rights reserved. No reproduction, copy or transmission of this publication may be made without written permission.

No paragraph of this publication may be reproduced, copied or transmitted save with written permission or in accordance with the provisions of the Copyright, Designs and Patents Act 1988, or under the terms of any licence permitting limited copying issued by the Copyright Licensing Agency, 90 Tottenham Court Road, London W1P 9HE.

Any person who does any unauthorised act in relation to this publication may be liable to criminal prosecution and civil claims for damages.

First published 1997 by

MACMILLAN PRESS LTD

Houndmills, Basingstoke, Hampshire RG21 6XS

and London

Companies and representatives

throughout the world

ISBN 978-0-333-64691-5

DOI 10.1007/978-1-349-13904-0

A catalogue record for this book is available from the British Library.

This book is printed on paper suitable for recycling and made from fully managed and sustained forest sources.

$\begin{array}{llllllllll}10 & 9 & 8 & 7 & 6 & 5 & 4 & 3 & 2 & 1\end{array}$

$\begin{array}{llllllllll}06 & 05 & 04 & 03 & 02 & 01 & 00 & 99 & 98 & 97\end{array}$

Copy-edited and typeset by Povey-Edmondson

Okehampton and Rochdale, England 
List of Figures

vi

List of Tables

vii

Foreword by Judith F. Hill

viii

Preface by Professor David Sines

ix

Acknowledgements

List of Contributors

xi

xii

Introduction

Carolyn Mason

1. Quality and quantity in community health care nursing Carolyn Mason

2. Consumer feedback and determining satisfaction with services

Brenda C. Poulton

3. Commissioning quality care: the purchaser's role

David C. Benton

4. Provider perspectives on quality in community health care

Maura Pidgeon

5. A practical approach to monitoring quality in community nursing practice

Hugh McKenna

6. Community child health care

Alison While

7. Achieving quality in residential care and nursing homes Robert Stewart and Ian Turner

8. Avoiding abuse amongst vulnerable groups in the community: people with a mental illness

Ann Long

9. Community health care nursing: its importance in general practice settings

Kate Cernik

Index 
2.1 Levels of user-involvement

3.1 The concentric commissioning cycles 60

3.2 Specification matrix using Donabedian and Øvretveit frameworks

3.3 Monitoring in context 68

3.4 Outcomes measures and utility to commissioners of care 69

5.1 The dynamic quality improvement cycle 
2.1 Government and patient-generated criteria of effective PHC services

2.2 Ranking of statements 40

2.3 Patients' criteria for evaluating their GP 41

3.1 Political drivers for change 55

3.2 Long-term purchaser-provider partnership benefits 61

3.3 Standard approach to specification structure 63

3.4 Key principles identified for the development of specification

3.5 Outcome measures that can be used in specification development

3.6 Themes covered by quality review visit 72

3.7 Process of quality review visit 73

5.1 Standard for leg ulcer care 103

5.2 Audit form 108

5.3 Audit record 113

5.4 Audit summary 114

5.5 Action plan for leg ulcer care 115

9.1 Jarman underprivileged area score - social indicators 193

9.2 Townsend deprivation score 194 
I want to commend the purpose of this book: 'to challenge community nurses to find and use quality approaches and tools which are applicable to their areas of practice'. The aim is to 'stimulate ideas and encourage action to achieve and demonstrate quality in ways that are considered to be appropriate by community nurse specialists themselves'.

Community health care nurses have responded in many positive ways to the challenge of the recent years. I believe this book will assist them to go on delivering accessible, responsive, patient/clientcentred services, in a whole range of settings, which will be effective in achieving good health outcomes for individuals, families, groups and communities.

The book is a timely contribution, and Dr Carolyn Mason is to be congratulated in bringing together a range of contributors who have approached the subject from different perspectives and provided a spectrum of solutions for community nurses to reflect on, try out and evaluate and from these activities to select ways of seeking to improve their practice.

JuDith E. HILL Chief Nursing Officer Department of Health and Social Services Northern Ireland 
Successive governments have indicated their commitment to enhancing the health of the nation and, in recent years, the focus of care delivery has shifted with escalating speed into the community. In so doing, it has become evident that community nurses and health visitors provide the focus for the promotion of health gain, and for the maintenance of positive health status for individuals, groups and local communities. Community nurses and health visitors are destined, therefore, to become leaders in the design, delivery and evaluation of effective health care interventions, informed by academic discovery, and advanced practice skills and competencies.

The changes that confront the contemporary community nursing practitioner are characterised by the diverse nature of the context within which community care is transacted, with an increasing emphasis on inter-sectoral co-operation, interprofessional collaboration, community action and development, and reduced reliance on the acute sector and residential care provision for longer stay client groups.

The impact of change, pushed by a growing demand for flexible, high-quality services provided within local communities, will inevitably shape the NHS of the future. Resources have already been shifted to the community (although at a pace that is all too often criticised as being grossly inadequate to meet client need). Commissioners and providers are now required to demonstrate that the care they purchase and deliver is effective and responsive to the needs of local practice populations. To complement this, community nurses will be required to ensure that their activities make a significant impact on health gain for their practice population and, as such, must become seriously involved in structuring the political agenda that ultimately governs their practice environment.

In order for the community workforce to respond to these challenges, it will be necessary to ensure that community workers are equipped with the necessary skills and knowledge base to be able to function effectively in the "new world of community health practice'. Nurses will be required to develop and change, drawing upon the very best of their past experience, and becoming increasingly reliant upon the production of research evidence to inform their future practice.

This series is aimed at practising community nurses and health visitors, their students, managers, professional colleagues and com- 
missioners. It has been designed to provide a broad-ranging synthesis and analysis of the major areas of community activity, and to challenge models of traditional practice. The texts have been designed specifically to appeal to a range of professional and academic disciplines. Each volume will integrate contemporary research, recent literature and practice examples relating to the effective delivery of health and social care in the community. Community nurses and health visitors are encouraged towards critical exploration and, if necessary, to change their own contribution to health care delivery - at the same time as extending the scope and boundaries of their own practice.

Authors and contributors have been carefully selected. Whether they are nurses or social scientists (or both), their commitment to the further development and enrichment of health science (and nursing as an academic discipline in particular) is unquestionable. The authors all demonstrate knowledge, experience and excellence in curriculum design, and share a commitment to excellence in service delivery. The result is a distillation of a range of contemporary themes, practice examples and recommendations that aim to extend the working environment for practising community nurses and health visitors and, in so doing, improve the health status of their local consumer populations.

Contributors to Achieving Quality in Community Health Care Nursing, edited by Dr Carolyn Mason, highlight specific quality issues relevant to practice in the United Kingdom. The book provides a critical appraisal of quality models and approaches relating to consumer feedback, resource management and a range of client groups. Rooted in the commissioner-provider context of contemporary community health care nursing, the authors articulate the importance of evidence-based practice. Readers are provided with a range of measurement tools designed to assist service evaluation. Furthermore, the authors analyse existing concepts of care delivery and challenge practitioners to develop new ways of achieving excellence in the workplace. 
I would like to thank all those who contributed to this book, especially Barbara Collins for secretarial support and the Eastern Health and Social Services Board Northern Ireland for resource and technical support. Not least, I would like to thank the anonymous reviewers who commented on the first drafts of the chapters, and David Sines as Series Editor for his helpful guidance and encouragement.

Carolyn Mason 
David C. Benton RGN, RMN, BSc, MPhil is Regional Nurse Director for the NHS Executive, Northern and Yorkshire.

Kate Cernik BSc, RGN, RHV, CertEd is Nurse Practitioner, Windmill Hill Surgery, Runcorn, Cheshire.

Ann Long RGN, RMN, HV, DipN, RNT, RHVT, BSc, MSc is Lecturer in Nursing and Health Visiting at the University of Ulster, Northern Ireland.

Carolyn Mason RGN, RHV, RNT, BA, PhD is Lecturer in Nursing at the Queen's University of Belfast and Assistant Director of Nursing, Eastern Health and Social Services Board.

Hugh McKenna RMN, RGN, DipN, AdvDipEd, RNT, DPhil is Senior Lecturer in Nursing at the University of Ulster and Chair of the Northern Ireland Dynamic Quality Improvement Network.

Maura Pidgeon RGN, RM, BSc, MBA is Nurse Clinical Specialist in Elderly Care, Craigavon Area Hospitals Group HSS Trust.

Brenda C. Poulton RGN, RHV, BA, MSc, PhD is a Research Officer in the Daphne Heald Research Unit of the Royal College of Nursing.

Robert Stewart RGN, RNT, CNS is Director of Nursing, Glenafton, Nursing Home, Glasgow.

Ian Turner BSc, CEng, MBCS, AFIMA is Director of the Registered Nursing Homes Association and Proprietor of Risby Hall Nursing Home, Suffolk.

Alison While RGN, RHV, RHVT, BSc, MSc, PhD, CertEd is Professor of Community Nursing at King's College, London. 